\title{
Towards understanding how individuals with Inflammatory Bowel Disease use contemporary social media platforms for health-related communications
}

\begin{abstract}
$\underline{\text { Abstract }}$
With a growing prevalence of social media use worldwide where individuals share varying aspects of their lives, this paper focuses on how individuals with a chronic illness use these communications platforms to discuss their health. This paper aims to provide a qualitative approach to understanding the connection between the technical features offered by Facebook, Twitter and Instagram and the therapeutic affordances experienced. Semi structured interviews were carried out with 38 participants living with Inflammatory Bowel Disease who use Facebook, Twitter and/or Instagram for healthrelated support. Interview transcripts were analysed systematically to draw connections between platform features and therapeutic affordances. The interview data was thematically coded through an adapted SCENA Model to infer therapeutic affordances, while content analysis identified the technical features discussed. Our findings indicate that most participants (79\%) use more than one social media platform for health-related discourse and that features on the platforms offer different therapeutic affordances. Facebook Groups' privacy settings affording self-presentation as individuals feel comforted that other people cannot see what they post, while hashtags afford connectivity on Twitter and Instagram, but not on Facebook. This dual approach enabled the authors to identify similarities and differences between social media platforms and their technical features through a qualitative approach.
\end{abstract}

\section{Keywords}

Social Media; Inflammatory Bowel Disease; Affordance Theory; Human Computer Interaction

This work was supported by the Horizon Centre for Doctoral Training at the University of Nottingham (RCUK Grant No. EP/L015463/1).

\section{$\underline{\text { Introduction }}$}

Affordable devices, widespread internet connectivity and free to access social networking platforms has resulted in a growing number of people using digital technologies to connect with others. Through the internet, individuals network with friends, family, co-workers as well as with strangers in online communities. Some of these communities are support orientated, fostering emotional and information support [1-5] for individuals with acute and chronic health conditions [6].

Social Media Platforms are web-based applications that "facilitate the development of social networks online by connecting a profile with those of other individuals and/or group," (p.747) [84]. Individuals create profiles and populate them with personal information and other user-generated content. The platforms are typically accessible on different devices such as computer-based browsers as well as smart phones and tablets making them convenient to access throughout the day. Social media platforms are becoming more prevalent in everyday life with several billion people using platforms such as Facebook across the world [44]. Research indicates that social media platforms have been adopted by support communities for health-related communications. One chronic illness that has a social media presence is Inflammatory Bowel Disease (IBD), an autoimmune condition that affects over 300,000 people in the UK and over 1.5 million people in the USA [7,8]. Several thousand patients with IBD use internet technologies to engage with online communities [6] distributed over multiple platforms, from web-based forums to social media $[38,49,73]$.

This paper seeks to answer the two research questions pertaining to the uses of social media platforms by the IBD online health communities through an affordance theory perspective. The questions are: 
First, literature on IBD and online health community $(\mathrm{OHC})$ research, is presented to give context to the study's purpose and research questions. We then outline the study's approach and share findings of how people with IBD use Facebook, Twitter and Instagram, and compare the differences reported. The paper concludes with key observations and suggestions for future work.

\section{Background}

\section{Inflammatory Bowel Disease}

Inflammatory Bowel Disease (IBD) is a lifelong, incurable and unpredictable illness that affects the gastrointestinal tract [16]. People living with Crohn's disease and ulcerative colitis, the two main types of IBD, experience gut inflammation caused by inappropriate immune responses [17].

Gastrointestinal inflammation materialises through symptoms including (but not limited to) chronic diarrhoea, abdominal pain, fevers, fatigue and weight-loss [16-18]. Without a known cure [19,20], patients with IBD have to undergo a lifetime of care which will often include the prescription of different medications from anti-inflammatories to biologic treatments, and in some cases invasive surgery [16,21]. People with IBD report having a lower quality of life as a result of absence from work, school and withdrawal from social activities, ultimately having a negative impact on patients' mental well-being [21-24]. In a systematic review of the health and social needs of people living with IBD conducted by Kemp et al [20], it was observed that "individuals expressed feeling damaged, a failure, weak and feeble with overwhelming feelings of anger, frustration and depression," (p.6, 2012). Patients may also become reclusive [25] and distant from family members [26] who may struggle to empathise with their experiences.

Therefore people with IBD may also require socio-emotional support to help them cope with the psychological implications of the illness. With the assistance of primary care providers and charities, patients may have access to face-to-face support groups to meet others. The growing prevalence of connective technologies has afforded new opportunities for patients to seek socio-emotional support in a more convenient way through the internet.

\section{Online Health Communities}

Online health communities (OHCs) are a series of "virtual discussion groups" [27] distributed across the Internet. From a social support theory perspective [80], digitally mediated communities have been shown to provide an accessible venue through which social support can be exchanged, including information, emotional, network and esteem support [29,30]. Information support is one of the most frequently observed types of social support in OHCs, as patients can share factual and experiential information about their illness and treatment options [77]. Social media benefits patients with the sharability and discoverability of information [39]; signposting patients to support groups and other websites $[39,40]$. The spread of information may also lend itself to the proliferation of misinformation $[35,42]$. The sharing of unsubstantiated information such as alternative medicine and diets may cause harm to patients who use it to make decisions around their medical care [43]. Emotional support is the other most common support type associated with OHCs [77]. Patients receive empathy and encouragement that helps them feel that they are not alone [85].

The internet offers a more convenient way for patients to access support. OHCs are available to patients 24/7, 365 days per year [4] and they have the choice to access different communities [2]. Posts are stored on servers so patients can benefit from asynchronous conversations with others from all over the world as well as having access to the accumulation of posts shared over time [4]. This means that people with mobility issues, fears of incontinence, or who live in more rural areas, can participate in OHCs without travelling [80]. However, as a consequence of global connectivity and distributed communities, tangible support is not frequently observed in OHCs [9].

A key benefit reported by users of OHCs is the ability to be anonymous, should they wish, which means that there is an inability for other users to identify their real-world identity $[2,30,33]$. Web- 
based forums and some social media platforms give individuals the ability to create screen names instead of using personally identifiable information. Without being personally identified, anonymity is reported to positively impact on people's willingness to self-disclose without risk of shame [4]. However, some contemporary social media platforms, such as Facebook, require users to use their 'real identity' as a trust mechanism [34] making anonymity more difficult on some contemporary platforms. Furthermore, while screen names may decrease identification from other users, other personal information credentials, such as email address and date of birth are collected by the platforms [82].

Patients with IBD have been reported to access online social support through web-based forums [45,65,70-71], as well as contemporary social media platforms Facebook $[5,37,38]$ and Twitter $[6,38]$. Other apps such as MyCrohnsandColitisTeam are also available for individuals with IBD to access social support [78-79]. Web-based forums have been a popular choice of platform for examination for OHCs for IBD and other illnesses. Though some web-based forums are still active for the IBD community, health-related communications are prevalent across multiple social media platforms. With individuals using social media platforms to leverage their personal, professional and interestdriven networks, it seems fitting that further investigation should be conducted across multiple platforms. The following subsections will share the current literature on popular contemporary social media platforms and how they have been used by the IBD community.

\section{Facebook}

Facebook is the world's largest social media platform with over two billion users [44] and it has been the focus of IBD-related studies between 2014 and 2016 [4,49,38,72,73]. Facebook Groups are reported as a popular place for patients to seek emotional support and information support $[5,45,46,49]$. Previous $\mathrm{OHC}$ studies have indicated that emotional support is more common than information support in health-related Facebook communities [12,47]. This may be because Facebook Groups provide users with a contained space to talk about their health issues separately from their day-to-day Facebook use; however, currently there is no evidence to suggest that this is the case for people with IBD.

When comparing Facebook Groups to well established web-based forums, Coulson [4] identified demographic differences between IBD patients that use them finding that Facebook users are typically younger and more educated than web-based forum users. Web-based forums users report accessing the platform more often and for longer periods over Facebook Group users. Reasons for this may include the awareness that Facebook Groups existed and pre-established relationships and culture in web-based forums. The quality of life and perceived stress between patients using web-based forums and Facebook were similar indicating that neither one was significantly 'better' for patients than another. While Coulson's 2013 study [4] provides some insight to the comparative differences between web-based forums and Facebook, there are other contemporary social media platforms that have been identified to be used by the IBD community. Furthermore since 2013 Facebook's userbase has doubled [74] and Facebook Groups such as Get Your Belly Out and Crohn's Colitis UK were set up, connecting thousands of patients [75,83]. It would be beneficial to the research community for a more up to date study to identify how Facebook is used as well as its perceived affordances.

\section{Twitter}

Twitter was established in 2006 as a social networking site that offers registered users the ability to 'microblog' through character-limited posts. Co-founder Evan Williams suggested that Twitter was built less as a social network but more as an information network, using hashtags to categorise tweets [49]. Hashtags soon became a central feature to the platform.

OHCs have also used Twitter to access online support $[6,42,47,49,73]$. Unlike Facebook, it is identified as a place less for emotional support, but more for information seeking and sharing [47], which supports Williams' vision for the platform to network information. Medical professionals have 
a greater presence on Twitter for health-related social media use than Facebook [47]. This means that there is the potential for patients to be exposed to more factual information, negating the risks from the spread of misinformation [76] as professionals can debunk and flag incorrect information.

Synchronous 'Twitter chats' are weekly one-hour chats for patients to talk about issues related to their illness including medications, symptoms, surgery, pregnancy, hint and tips [6]. The collated tweets act as additional resources for patients who wish to review multiple perspectives on the same issue. Seres reported that while patients do use Twitter for information support, "this environment [is used] to provide vital support to others experiencing similar situations," (p142) [6] demonstrating that socioemotional support is present on the platform.

\section{Instagram}

Founded in 2010, Instagram is a picture-based social media platform with over one billion users [52]. Users share pictures and videos on their profile through 'posts' or 24-hour 'stories', and have the ability to contextualise images with location, captions and hashtags. Users can 'like' and comment other people's posts as well as respond or 'react' to Instagram 'Stories'. An Instagram user's profile typically has a profile picture, username, number of posts, followers and following (similar to Twitter profiles). The users' posts appear as a triptych grid in reverse-chronological order.

There are limited studies that explore the IBD online health community on Instagram; to the best of our knowledge there is only one peer-reviewed paper. Szeto et al [52] found that Instagram and Facebook were more popular social media platforms for health-related self-expression by young IBD patients; however, for this age group of the participants (12-25 years) a small proportion (16\%) of the participants reported to use social media to connect with the IBD community.

There are however some insights into Instagram's use by other communities, particularly around mental health [54-58]. A study by Andalibi, Ozturk and Forte [54] found that patients appear to use narrative through Instagram posts to make sense of their mental health. The picture sharing feature, that is central to the platform's architecture, has been observed as a tool for people with illnesses to raise awareness, and shape their identity over time [60,61]. Patients who share posts typically create hashtags as a means to engage with particular communities as well as being used as semantic markers, providing additional context to their posts [54]. Finally, distressed or negative posts typically receive positive comments [54], demonstrating socio-emotional support functions. This paper perceives Instagram to be a place less for information seeking and sharing, but for socio-emotional support within the mental health online communities.

\section{Affordance Theory}

Previous research investigating OHCs, including IBD $[5,71]$ have adopted survey and digital ethnographic methods to understand how social interaction benefits people living with chronic illnesses. Through a social support theory lens, prior studies demonstrate how information sharing and emotional support make up a significant proportion of the posts shared in community spaces [77]. With agreement in the literature about the social support interactions in online health communities, attention has turned towards understanding how the therapeutic outcomes of using digital technologies can be understood through an affordance theory perspective [15,81].

Affordance theory is based on how individuals perceive their environment, identifying objects within it and the potential actions the objects can afford [59]. In The design of everyday things (1988) Norman [87] emphasised the importance of object design so that individuals can perceive their affordance before taking action. This design approach positions technologies as objects with functional, cognitive and sensory affordances and has been significantly referenced in human computer interaction (HCI) research. Hutchby [88] argued however, that while functional affordances are built into objects, the experienced affordances are open to interpretation. Individuals bring their own preferences, beliefs, motivations, and, experiences to an object; these converge to allow the 
affordances to be realised [89]. This support Norman's notion that everyone's experience of objects is unique [87].

To understand how social media broadly affords therapeutic outcomes for people in OHCs, Merolli et al [15] developed the SCENA Model of Therapeutic Affordances of Social Media (SCENA). The model (Figure 1) was developed through thematic analysis of qualitative survey data from a chronic pain community. The affordances identified included self-presentation, connectivity, exploration, narrative and adaptation. Self-Presentation is the means in

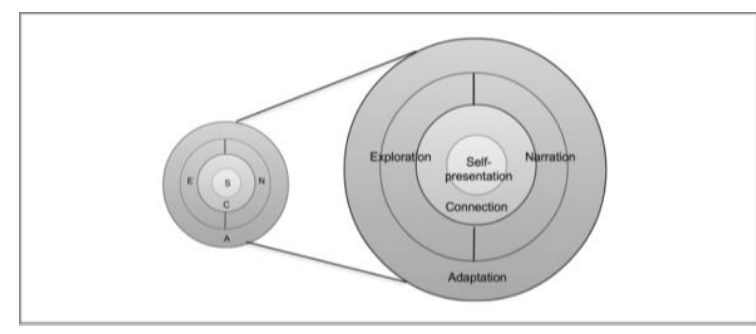

Figure 1: The SCENA Model of Therapeutic Affordances, Merolli et al., 2014 which a patient can express an identity through their profile, postings and privacy controls; Connectivity, offers the means to connect with other patients and healthcare practitioners; Exploration, the seeking and sharing of information; Narrative, the seeking and sharing of patient experiences; and, Adaptation, the ability to use the platforms when they wish.

The SCENA model moves away from observing the conversations between users and begins to explain the affordances as a result of the interactions people have with other people online as well as the technology, and its functions. In an ethnographic study of how diabetes patients aggregate on Twitter, Bernardi [90] observed a community through composite affordances, based on Merolli et al's model of therapeutic affordances [15], and the role of digital objects. That study extended knowledge about the materiality of social media and its functional uses to support online communities. A limitation of this study, however, is that it neglects some functionality, such as direct messages, and the nuanced uses of technical features, such as Twitter chats [6].

\section{$\underline{\text { Research Focus }}$}

Though IBD has been the focus of previous OHC research, in a 2016 review Guo et al [38] concluded areas that require further research, including the usage and preferences of different social media platforms by IBD patients. Furthermore, with affordance theory as a lens to understand the functional and composite possibilities of social media, there has been a call for researchers to focus on specific social media platforms rather than treating them as a collective [81]. The purpose of this study is to understand how therapeutic outcomes are realised through the technological features offered by social media platforms, which inspired the first research question:

\section{RQ1: How do platform features and functionality influence therapeutic affordances?}

The literature surrounding the IBD online health communities have typically focused on specific platforms such as web-based forums [4,65,70,71], Facebook [5,49,38,72,73], Twitter [6,49,38,73] with one paper exploring the transition between paediatric and adult care on Instagram [53] and one comparison paper between Facebook and web-based forums [4]. Previous papers offer observations of the support behaviours in OHCs, and the benefits of digital technology. However to the best of our knowledge, there is not any published research that explores how multiple social media platforms are used by the IBD OHCs through an affordance theory lens, and whether they offer comparible experiences and affordances to their users. As such, the second research question is:

\section{RQ2: How do therapeutic affordances differ between Facebook, Twitter and Instagram?}

\section{$\underline{\text { Methods }}$}




\section{Ethical Approval and Recruitment}

A participant information sheet, consent form and the interview questions were submitted to and approved by the Computer Science Ethics Committee at the University of Nottingham in January 2018, giving permission to begin recruitment in January 2018.

Advertising posts were shared across Facebook, Twitter and Instagram to recruit participants with IBD for the study, offering a $£ 10$ voucher (or equivalent) to compensate for the participants' time and support. To qualify as participants appropriate for the research focus, participants had to declare that they both had been diagnosed with IBD and used social media to engage with other people in the community. For safeguarding purposes and to mitigate for unintentional distress, individuals were asked to self-declare whether they felt well enough to participate.

\section{Interview Methods}

In order to understand how people with IBD use Facebook, Twitter and Instagram, semi-structured interviews were selected. While previous research used digital ethnographic methods with affordance theory [90], they were limited in the data that could be collected; for example, direct messages are not publicly available for research purposes. When affordances are open to interpretation semi-structured interviews allowed the interviewer to ask open and follow-up questions to understand the nuances of how people have used the platforms, and the outcomes that they have experienced. Furthermore, for participants to engage in interviews they must engage with the consent process, giving them agency over whether they are comfortable with sharing their experiences. Digital ethnography raises privacy risks when members of the communities have not given consent for their information to be used; identifying challenges around misinterpretation and context collapse [93].

Patients with IBD who engage with online health communities are distributed around the world and face-to-face interviews would require significant resources; therefore, participants were invited to be interviewed over the phone or Voice over Internet Protocol (VoIP). Previous research has suggested that participants may be more comfortable with interviewing through internet-enabled devices as it gives them some agency over where they wish to conduct the study $[62,63]$ such as in their own home.

The audio-recorded interviews were divided into three different sections. The first section participants were asked to share their story with their IBD. The aim of this was to help ease any apprehension with being recorded and share something familiar to them [69]. The second segment focused on the participants' experience of using social media platforms for IBD-related communications. Questions included but were not limited to: (a) Can you share your experience using Facebook/Instagram/Twitter with regards to your IBD? (b) What sorts of things have you shared on social media with regards to your IBD? (c) what technical features do you particularly find useful when using Facebook/Instagram/Twitter for IBD-related communications, and (d) what technical features do you not find useful when using Facebook/Instagram/Twitter for IBD-related communications? The third section invited participants to talk about their risk perceptions sharing health-related information on social media. This paper pays attention to the findings from the second part that explores patient experiences using social media platforms.

\section{Analysis}

Audio recordings of the interviews were transcribed by the first author $(n=33)$ and a third-party transcription service $(n=5)$. The transcripts were analysed using deductive thematic analysis to identify themes of affordance theory, according to the SCENA model [15]. A random set of 4 transcriptions were sent to the second and third authors to assess inter-coder reliability. Inter-coder reliability is widely used to examine the extent to which independent coders agree on the coding of 
the transcripts (i.e., if similar themes/coding scheme was identified). This process was conducted early on the thematic analysis process to ensure consistency in the remaining data analysis.

The coding structure presented by Merolli et al [15] acted as a guide towards coding the transcripts. While the affordances remained the same, the coding structure was adapted (Table 1). When participants discussed a specific technical feature, such as 'comment' or 'tweet', and described a therapeutic affordance, the excerpt was extracted into a table (See Appendix) for further analysis and discussion. If a participant was making a general remark about a platform, it was discounted from this analysis.

\begin{tabular}{|c|c|c|}
\hline Language & Theme & Affordance \\
\hline $\begin{array}{l}\text { Privacy } \\
\text { Control } \\
\text { Audience } \\
\text { Disclosure } \\
\text { Safety }\end{array}$ & $\begin{array}{l}\text { Disclosure } \\
\text { Control } \\
\text { Identity }\end{array}$ & Self-Presentation \\
\hline $\begin{array}{l}\text { Finding others } \\
\text { Discoverability } \\
\text { Speaking to others } \\
\text { Commenting } \\
\text { Chat }\end{array}$ & $\begin{array}{l}\text { Inclusion } \\
\text { Interaction } \\
\text { Networking } \\
\text { Mitigating isolation } \\
\text { Empathy } \\
\end{array}$ & Connection \\
\hline $\begin{array}{l}\text { Information about disease, } \\
\text { treatments and surgeries. } \\
\text { Research. }\end{array}$ & $\begin{array}{l}\text { Directive Information seeking } \\
\text { (Prescott et al., 2017) } \\
\text { Directive Information sharing } \\
\text { (Prescott et al., 2017) }\end{array}$ & Exploration \\
\hline $\begin{array}{l}\text { Stories } \\
\text { Journey } \\
\text { Personal experiences }\end{array}$ & $\begin{array}{l}\text { Non-directive information seeking } \\
\text { (Prescott et al., 2017) } \\
\text { Non-directive information sharing }\end{array}$ & Narrative \\
\hline $\begin{array}{l}\text { Unwell } \\
\text { Having a flare } \\
\text { Fatigue } \\
\text { Remission }\end{array}$ & Variation in use & Adaptation \\
\hline
\end{tabular}

Table 1: Coding structure for analysis, based on SCENA Model [15]

\section{$\underline{\text { Results }}$}

\section{Participants}

A total of 38 participants were recruited through Facebook $(n=9)$, Twitter $(n=16)$ and Instagram $(\mathrm{n}=13) .20(53 \%)$ participants were female and $18(47 \%)$ male providing an agreeable distribution. In the study, participants were asked to tell the story of their experiences with IBD; all 38 participants disclosed which IBD they were diagnosed with. 25 declared living with CD, 12 with UC and 1 with Indeterminate Colitis.

The majority of participants in this study $(n=30)$ use more than one platform for IBD-related purposes with the peak number being 3 platforms. Participants discussed using other platforms including Pinterest, YouTube, Forums and Snapchat; however, the number of cases for these was very low and therefore were not explored in this study. Instagram was the most popular platform used by participants $(n=28)$ followed by Facebook $(n=27)$ and lastly Twitter $(n=24)$.

All 38 transcribed interviews were coded by the affordances of Self-Presentation, Connection, Exploration, Narrative and Adaptation, as well as by the platform feature to which the phrases referred to. Only data that refer to both platform feature and an affordance were included for analysis. 


\section{Facebook}

Using the SCENA Model of Therapeutic Affordances to thematically code the data, 12 Facebook features were identified as affordance enablers. The data visualisation can be found in Appendix 1. Table 2 describes the number of coded references assigned to each feature and coded affordance.

\begin{tabular}{|c|c|c|c|c|c|}
\hline $\begin{array}{l}\text { Facebook } \\
\text { Features/Affordances }\end{array}$ & $\begin{array}{c}\text { Self- } \\
\text { Presentation }\end{array}$ & Connection & Exploration & Narrative & Adaptation \\
\hline Comments & - & 2 & 2 & 1 & - \\
\hline Files & - & - & 1 & - & - \\
\hline Groups & 12 & 3 & 2 & 1 & - \\
\hline Hashtags & - & 1 & - & - & - \\
\hline Live & - & 1 & - & - & 1 \\
\hline Messenger & 1 & 3 & - & - & 1 \\
\hline Page & 8 & 1 & - & - & - \\
\hline Polls & - & 2 & - & - & - \\
\hline Post & 1 & 1 & - & - & - \\
\hline Reactions & - & 2 & - & - & 1 \\
\hline Recommendations & - & 1 & 1 & - & - \\
\hline Settings & 2 & 1 & - & - & - \\
\hline
\end{tabular}

Table 2: Facebook features, affordances and number of excerpts assigned.

On Facebook, the most commonly referenced feature was the Facebook Groups. Facebook Groups were referred to as a venue through which people from all over the world connect in a collective, virtual and safe space for support. While most of the features discussed in the study are available through both pages and groups (Figure 2), in this study, $72 \%$ of the Facebook coding was represented by the discussion of features used within Facebook Groups. Unless stated otherwise, note that the following discussed features were described as being used within Facebook Groups.

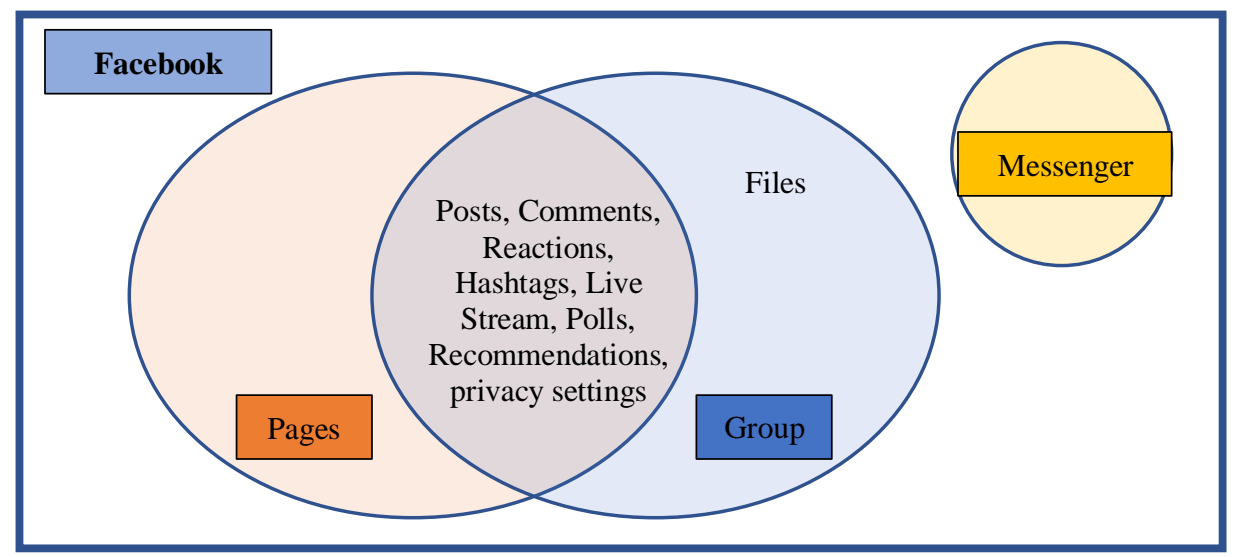

Figure 2 Visualisation of features on Facebook

Facebook Groups enable communities to "congregate in one place" (Participant 13) and connect with like-minded individuals who can empathise and provide some support. Individuals remarked on how having a space dedicated for support creates a "friendly environment to share your story [...] without somebody coming back with a critical remark or comment," (Participant 9). The notion of community creation in Groups is reminiscent of the connection affordance. However, 2 of the 5 coded excerpts 
refer to the negative outcomes of connectivity in Facebook Groups, indicating that there are disagreements within the communities. In larger groups individuals may find that they do not have their posts responded to, as a result of the algorithmic feed: "Whereas certainly with the Facebook groups you can put a comment up and just get nothing" (Participant 5).

The most frequently coded therapeutic affordance in the Facebook Groups data was self-presentation. In the analysis all the groups that were referred to were described as being 'closed' which means that the groups are discoverable in a search, but the posts are only accessible to members. The privacy aspect of the Facebook Groups was frequently discussed by participants, indicating that they afford a space for members to feel "safe" (Participant 36) to speak "openly" (Participants 9, 23, 32) and intimately (Participants 2, 13, 31) about their illness, away from other audiences such as family, friends and colleagues (Participants 1, 23, 32).

Connection was the most prevalent affordance across the features, being reported in 11 of the 12 features. Participants talked about speaking with others, exchanging stories and concerns about their health. They also use the reaction feature (like, love, dislike, shock, etc.) to help quickly communicate a sense of empathy.

"the likes and the hearts and the laughing out loud or the sadness, that's been good I guess because it shows like obviously if you post a really negative post while you're in hospital so many people like it, it's almost like why are you liking this?" (Participant 29).

Comments were reported as a common part of the Facebook experience, being the primary way in which people within Groups communicate with one another (connection). This is where members can share their experiences to help answer someone's concern (Participant 28). The accumulation of comments provides non-posters with a wealth of information and experiences to learn from (Participants 17, 36) which indicates how comments contribute to the exploration and narrative affordances.

The affordance of adaptation was least coded however, individuals described how the different features mean that they can still participate when they are not feeling well. Individuals described how they don't always post comments but can 'react' to posts in groups "because some days, that's all you can be bothered to do" (Participant 36). Furthermore, the 24-hour access means that some members end up privately messaging through the Messenger app late at night "because that seems to be when people are awake, perhaps they can't sleep because of the steroids or their mind is ticking over," (Participant 36).

\section{Instagram}

The features on Instagram are interlinked in a similar way to Facebook. Individuals have a profile from which they can create 'posts' and temporary Stories that last 24 hours. For each of these features, additional features of text captioning, hashtagging, geotagging and user tagging are available. Other users can connect with a post through likes and comments, while they can respond to Stories in a direct message. People can search other users and hashtags, or browse the 'Explore' tab that displays posts that are tailored to each user through Instagram's algorithm. Table 3 displays the features that were identified by 28 participants who used Instagram for health-related communications.

Connection was the most prevalent affordance being reported across 13 of the features. Several features were described to help patients find other people, network, and build communities. Participants described using hashtags to find other people (Participant 16, 19, 20, 26, 27, 33), as well as to increase the discoverability of their experiences to others (Participant 18, 21, 35). Photo-tagging was described as a tactic to grab the attention of particular accounts, strengthen a community (Participant 21), and to attribute other users (Participant 33). Instagram's algorithm will "suggest [to 
users] similar accounts and are more likely to suggest posts or hashtags" (Participant 30) enabling community members to discover new accounts and increase their network.

Unlike Facebook Groups, where individuals congregate in a central space, Instagram operates in a more distributed manner, encouraging users to 'follow' other users. Participants in this study remarked on how the 'follow' function enables a more tailored experience of who's story and experiences they wish to regularly view (Participant 21, 26). One participant described how they follow different interest pages on each of their accounts to compartmentalise their experience (Participant 30). It should be noted that not all of the affordances were considered to be positive. The algorithms that order posts on users' feeds were negatively associated with the affordance of connection. Participants described the algorithm to limit the audiences who might see their posts (Participants 18, 21, 26, 33) which ultimately limits their ability to raise awareness or seek support from others.

\begin{tabular}{|c|c|c|c|c|c|}
\hline $\begin{array}{l}\text { Instagram } \\
\text { Features/Affordances }\end{array}$ & $\begin{array}{c}\text { Self- } \\
\text { Presentation } \\
\end{array}$ & Connection & Exploration & Narrative & Adaptation \\
\hline Algorithms & 1 & 5 & - & - & - \\
\hline Comments & - & 2 & - & - & - \\
\hline Direct message & 2 & 4 & 2 & 4 & - \\
\hline Explore & - & 1 & - & - & - \\
\hline Follow & - & 2 & - & 1 & - \\
\hline Hashtags & 1 & 9 & 1 & 1 & - \\
\hline Hyperlinks & - & - & 1 & - & - \\
\hline Location & - & 1 & - & - & - \\
\hline Multiple Accounts & 3 & 1 & - & - & - \\
\hline Posts & 4 & 1 & 2 & 4 & - \\
\hline Search & - & - & 1 & - & - \\
\hline Share & - & 1 & - & - & - \\
\hline Stories & 3 & 5 & - & 4 & 1 \\
\hline Tagging & - & 3 & - & - & - \\
\hline
\end{tabular}

Table 3: Instagram features, affordances and number of excerpts assigned.

Participants also described features that enabled interaction between users. Comments and direct message are the two methods individuals can take to directly converse with another user (connection). Users can respond to posts through comments (Participants 27, 34), while they respond to Stories through direct message (Participant 27). Direct message affords connection and narrative so that patients can form relationships (Participants 21, 33, 35).

The next most frequently reported affordance was self-presentation. The features closely affiliated with self-presentation were posts, stories, multiple accounts, and direct message. Firstly, Instagram enables users to create more than one account for themselves, allowing users to portray different identities through each profile. Some participants in this study described using a separate account to compartmentalise their 'every day' life from what they will post about their illness. Some accounts might be public, meaning that their posts are discoverable in searches and non-followers can see their profile, while others might be made private to limit their audience. This compartmentalisation of identities indicates a sense of boundary-making in order to control who might see what information.

"this [account] is for me to connect with other people in the community and not for friends and family so you're welcome to follow it and my story, but this is my page to connect with other people and hear their stories, I don't need your stuff kind of my feed." (Participant 30) 
"So I made my privacy settings private when I set up my foodie Crohn's account because I wanted a line between my personal life and my professional blogging account" (Participant 26)

Participants demonstrated control over the information they are uncomfortable with sharing, choosing not to post information about their health on Instagram. Posts are 'memorialised' (Participant 16) on profiles. The accumulation of posts was recognised as a construction of an online identity; this may be carefully crafted so that individuals present themselves in a particular manner. Of the 28 participants who use Instagram, participants described having IBD-related accounts around fitness $(n=3)$, nutrition $(n=2)$, daily life $(n=2)$, positive living $(n=2)$ and support awareness $(n=1)$. However, not all participants have health-specific accounts, but may have "an IBD slash personal account that they might put in the odd photo here and there and the rest will be personal photos of their friends or their family," (Participant 26). Not all patients who use online health communities self-disclose about their health but will observe the community from the periphery, this is referred to as lurking $[65,66]$ and "peripheral participation" [67].

Instagram Stories offer a temporary, 24-hour, sharing of information to followers. Participants described how Instagram Stories affords the sharing of raw and in the moment emotions; one participant described Stories as "more immediate and personal" (Participant 26). Participant 16 said that "I share more on my stories because you know they're temporary I don't have to really think that hard about what I share". Stories provide a safety insofar that their information will not be permanently available on their profile. Notions of safety were also attributed to direct message, as this function was described to provide a more "comfortable" (Participant 20) and private environment to talk in detail about their illness with others (Participants 18, 20).

The seeking and sharing of narrative was reported through the feature of hashtags to find individuals who share about their IBD experiences (Participant 19), followed by following them if their content is something that a patient is interested in (Participant 26). Sharing experiences is reported to take place on a regular basis through Stories "I feel like with the stories it's more like vlogging and it's continuous," (Participant 20). Posts, specifically the captions, are also a feature that enables patients to share their experiences.

"in my caption maybe explain that I've had a bad day or what symptoms I've experienced and try and use that as a call to action or a positive message for other people who might be feeling the same," (Participant 26)

Not all experience sharing is broadcast on profiles through posts and stories. Participants described using more private spaces, such as direct message to exchange personal experiences (Participants 16, $21,26,27)$.

The seeking and sharing of directive information (exploration) was reported less than the theme of narrative. Participants described searching hashtags (Participant 16), looking at posts (Participant 17) and direct message (Participant 18) to as means to finding more information about surgery.

Information about diet, recipes and nutrition through posts was reported as particularly useful by Participant 23 who was struggling to find meals to help with their symptoms.

\section{Twitter}

Twitter had the fewest reported features of the three platforms with 10 reported features (Table 4). The features are less interconnected than on Facebook and Instagram. Profiles are centred around tweets which are 280-character limited posts that can include pictures, video, hyperlinks and hashtags. Users do not 'comment' but instead reply through another tweet.

Connection on Twitter was attributed to hashtags, follow, reply, polls and direct message. Hashtags were the most frequently reported feature of Twitter. One participant remarked that "Twitter is 
technically like the birthplace of hashtagging" (Participant 19) which might offer an explanation for its recurring discussion. Similar to Instagram, individuals congregate around hashtags that might interest them, finding others to interact with and feel part of a community (Participant 25, 29, 37, 38). Participants reported on scheduled synchronous gatherings around particular hashtags, such as \#IBDhour when patients and medical professionals discuss particular topics. These are called Twitter Chats (Participant 12, 13, 29 38). In these chats people can connect with one another and share information and experiences (exploration and narrative).

"it's called hashtag IBD hour and on a Thursday night you can follow conversations and questions to certain people who might be leading that talk and you can ask them online and get replies that way, that's quite good if you've got any concerns and the topic is what you want it to be. (Participant 13)

\begin{tabular}{|l|ccccc|}
\hline $\begin{array}{l}\text { Twitter } \\
\text { Features/Affordances }\end{array}$ & $\begin{array}{c}\text { Self- } \\
\text { Presentation }\end{array}$ & Connection & Exploration & Narrative & Adaptation \\
\hline Pinned Tweets & 1 & - & - & - & - \\
Retweet & - & - & 1 & - & - \\
Blocking & 1 & - & - & - & - \\
Direct Message & - & 1 & - & - & - \\
Polls & - & 1 & - & - & - \\
Multiple Accounts & 3 & - & - & 1 & - \\
Reply & - & 1 & 1 & - & - \\
Tweet & 5 & - & - & 2 & 1 \\
Follow & - & 3 & 3 & 1 & - \\
Hashtags & - & 9 & 5 & 2 & 1 \\
\hline
\end{tabular}

Table 4: Twitter features, affordances and number of excerpts assigned.

Participants reported on how medical professionals also participate in the IBD community on Twitter. Access to doctors (connection) means that patients can keep up to date with new research as well as receive factual information (Participant 1, 4). Participants also reported on using hashtags to search medical interventions to see what information they could learn about them (Participant 11, 12, 17). The searching for factual and directive information about their illness, treatments and surgery through hashtags and interaction with medical professionals is indicative of the affordance of exploration.

When patients have found others whose experience interests them, they might choose to follow them. Once following, the user's tweets will then appear in the follower's home feed, enabling a patient to keep up to date with their condition and experiences over time (Participant 34). The expectation that tweets will not offer great detail was described as a useful tool to quickly share experiences and feelings (narrative), participants $(1,19)$ remarked on the cathartic release on being able to externalise these thoughts online:

"so learning to talk about things has been one of the really good things about being online because I can just post it in like 140 characters and then I let it go," (Participant 1)

Participants reported on how Twitter's features influences self-presentation in a restrictive way. Twitter employs a strict character limit on tweets, which for participants means that they have to "think more" (Participant 8) about how they can "best get across how I'm feeling today in the limited number of characters I've got" (Participant 11). This strict limit was frequently associated with the self-presentation affordance for it restricts how much detail an individual can write about. Two participants however described the 'threading' of tweets, whereby tweets are tied together, providing more room to share longer posts (Participant 1, 19). For some participants separate blogs were used to talk about experience at length, while Twitter was used to promote the hyperlink (Participant 1). 
Participants described how the blocking tool can support them in controlling their audience and safeguard themselves from unkind users and unsolicited advertising (Participant 11). Another audience management tactic, similar to Instagram, is the adoption of multiple accounts. Participant 19 described their two accounts, one for professional use and another as a "place of like I share my thoughts and everything and also I just leave it as a bedpost of like say here's anxiety or here's depression and there you are." The use of multiple accounts to create boundaries between audiences may help individuals feel safer to self-disclose and explore their identity as a person with a chronic illness.

Finally, the low-effort required by individuals affords continued participation in the community, even during times when the illness is difficult to manage (adaptation). The shortness of tweets can be particularly helpful "if you've got chronic fatigue, or you've had a long day, or you're in loads of pain, you don't want to sit then, and read a really long thing," (Participant 36).

\section{$\underline{\text { Discussion }}$}

This study exploring the technical features of Facebook, Twitter and Instagram in relation to therapeutic affordances, has presented new insights as to how the IBD communities operate across different contemporary platforms. This study focused on whether therapeutic affordances can be attributed to specific technical features (RQ1), and whether there are different affordances and experiences across Facebook, Twitter and Instagram (RQ2).

Applying a coding procedure, adapted from the SCENA model [15], we were able to identify what features people with IBD used on three different social media platforms to engage with the OHCs. There were some features that were exclusive to the platforms. On Facebook, these included the Facebook Groups; post 'reactions', affording connection; and, files, affording information retrieval (exploration). While on Instagram, Stories were unique affording self-presentation, connection, and, narrative. However, the platforms mostly shared similar technical features including making posts, hashtags, search bar, comment, tag and instant message. These features all afforded the same therapeutic outcomes across the platforms; however, in our analysis, we observed that there were variances in use for each platform.

It was observed that the ways in which technical features were integrated into the platforms' interfaces had an impact on how they were used by participants, and how frequently. For instance, on Facebook, few participants reported using direct message because the Facebook Groups already provided privacy controls; however, on Instagram, direct messaging is the vehicle for which people reply to Stories. With Instagram being a public-facing platform, direct message was used more often to allow people increased privacy controls to discuss more sensitive matters (self-presentation). Conversely, despite Twitter having a similar public facing architecture, direct messaging was infrequently reported in this particular study. The notion of hidden and sequential affordances relates to Gaver's definition that affordances are either "sequential in time or nested in space" (p. 82). It could be said that the use of direct messaging in Instagram to respond to Stories might encourage more intimate, private conversations, fostering meaningful interactions between community members than other features such as 'liking'.

While some features were available across all three platforms, other features might have limited their use and affordances, such as hashtags. Their use on Facebook was infrequently reported and was described as ineffective, with the increased privacy settings on the platform. Both Twitter and Instagram's privacy settings are more binary which means searching public posts through hashtags is easier and more effective. Hashtags on Twitter and Instagram were reported to find others (connection), build communities (connection), find and share information (exploration) and experiences (narrative). Furthermore, the 240-character limit on Twitter, combined with the public facing profiles, restricted how much people chose to self-disclose about their personal experiences (self-presentation). 
The examination of multiple contemporary social media platforms not only enabled the investigation to the uses of each platform but indicated that patients use several for health-related communications. In this study 30 participants (79\%) used more than one platform to access IBD-related OHCs. Surveys of the general population suggest that multiple social media platform use is common outside of the health field [86]. This is likely due to the low or non-existent price to access platforms and cloud-base storage facilities, making accessing several applications on a smartphone more convenient. It would be reasonable to expect that the multiple use of social media platforms for IBD-related communications is an outcome of normalised multi-platform use. We infer that the uses of multiple social media platforms for health-related support may impact on how people use each one. For instance, if people find that they have a safe space to discuss their experience in Facebook Groups, feeling a sense of control over their personal information, then they might use Twitter as a platform for exploration affordances, seeking factual information or interacting with health professionals.

The coding structure of the SCENA Model indicates that often individual platform features can offer multiple affordances. For instance, commenting or replying to a post affords connection and potentially exploration, narrative and self-presentation, depending on how the feature is used and what is disclosed. For each individual, the way in which a feature is used is going to impact on the affordances that are experienced. The features that are offered may also influence behaviours, such as closed Facebook Groups offering privacy protections that enable higher self-disclosure. Yet, while designers create functionality to encourage particular behaviours, each individual has their own motivations and preferences over what they feel comfortable self-disclosing online [91,92].

While this adapted use of the SCENA model has contributed towards a better understanding of how people with IBD use social media platforms, it has also further highlighted the nuanced nature of platform use; based on individual motivations, health status (adaptation), digital literacy, multiple platform use, and, privacy preferences. Indeed, these findings further supports previous research indicating that affordances are personal and open to interpretation [87,88]. Ultimately, however, the ability for people with IBD to have access to multiple platforms, features, and therefore communities, means that there is ample opportunity to receive social support. Future works can focus on sequential affordances and how together affordances enables meaningful communities, as well as how far features, and their perceived affordances, influence disclosure behaviours.

\section{Limitations and future works}

The participants that were recruited for this study were typically active sharers of their health information, with one participant who considered themselves as a 'lurker'. From social media research, this selection is not representative of the community, as typically a small minority of community members create content $[49,66]$. This misrepresentation of the community is partly due to the self-selecting nature of interview participants. Nevertheless, given that this study aimed to understand how platforms and their functions are used, interviewing patients who have lived experiences of self-disclosing health information was useful.

It is worth noting that the results from this study should not be analysed in a quantitative manner. It is likely that the number of affordances and features coded in this study do not represent community behaviours at scale. For instance, previous research of online health communities indicate high levels of information sharing $[1-4,12,28,47,54,71]$ however in this current study, notions of connection and self-presentation were more frequently coded. The analysis method that excluded general remarks about platforms, was employed as a means to test whether features are linked to specific affordances. Future works may take a more quantitative approach to substantiate the findings from this study; however, we do urge that researchers are sensitive to the contextual nature of platform use as mentioned above.

\section{$\underline{\text { Conclusion }}$}


The findings from this study offer the research community insight into the specific affordances of features as told by people living with IBD. Through a qualitative approach, the current study evidences that each of the therapeutic affordances outlined by Merolli et al [15] are experienced through Facebook, Twitter and Instagram. We achieved this by applying an adapted SCENA framework, focusing on the therapeutic affordances of specific platform features discussed by participants. Each of the platforms provide similar functionality and we conclude that notions of connectivity underpin social media use for health-related communications, for information and experience sharing. In response to the research questions, while there are many similarities between the platforms, the ways in which they are experienced, and consequently the affordances actualised varied. We found that the limitations of features, such as character and time limits on posts, can have an influence on what people might self-disclose. Secondly the way in which features are organised and experienced in the platform, such as direct messaging in response to Instagram stories, can have an influence over the affordances experienced. Finally, individuals have their own preferences and motivations for participating in online health communities on the internet which will influence platform use over time.

\section{$\underline{\text { References }}$}

1. Coleman, L. J., Shah, N., \& Jain, S. (2015). The Impact of Demographic Characteristics on Awareness and Usage of Support Groups. Health Marketing Quarterly, 32(3), 272-288. https://doi.org/10.1080/07359683.2015.1061863

2. Turner, J. S. (2017). Social Media and Healthcare: an Analysis of Research and Limitations. Southern Illinois University Carbonda Le, (Spring). Retrieved from http://opensiuc.lib.siu.edu/gs rp

3. Lewinski, A. A., Vorderstrasse, A. A., Anderson, R. A., Pan, W., Fisher, E. B., \& Johnson, C. M. (2017). Analyzing Unstructured Communication in a Computer-Mediated Environment for Adults With Type 2 Diabetes: A Research Protocol. JMIR Research Protocols, 6(4), e65. https://doi.org/10.2196/resprot.7442

4. Coulson, N. S. (2013). How do online patient support communities affect the experience of inflammatory bowel disease? An online survey. JRSM Short Reports, 4(8), 204253331347800. https://doi.org/10.1177/2042533313478004

5. Coulson, N. S. (2015). Exploring patients' engagement with web-based peer support for Inflammatory Bowel Disease: forums or Facebook? Health Psychology Update, 24(2), 3-9. Retrieved from http://www.healthpsychologyconsultancy.co.uk/documents/HealthbaselinecomparisontheoryAdjustmenttorheumatoidarthritis.pdf

6. Seres, M. (2014). The Role of Social Media in Healthcare: Experiences of a Crohn's Disease Patient. in R. K. Bali et al. (eds.), Rare Diseases in the Age of Health 2.0, 139

Communications in Medical and Care Compunetics 4, DOI: 10.1007/978-3-642-38643-5_15, (C) Springer-Verlag Berlin Heidelberg 2014

7. Crohn's and Colitis UK. (n.d). About Inflammatory Bowel Disease. Retrieved from https://www.crohnsandcolitis.org.uk/about-inflammatory-bowel-disease

8. Crohn's and Colitis Foundation of America. (n.d.). What are Crohn's and Colitis? Retrieved from http://www.ccfa.org/what-are-crohns-and-colitis/

9. Coulson, N. S. (2005). Receiving social support online: An analysis of a computer-mediated support group for individuals living with irritable bowel syndrome. Cyberpsychology and Behavior, 8(6), 580-584. 
10. Coulson, N. S., Smedley, R., Bostock, S., Kyle, S. D., Gollancz, R., Luik, A., ... Espie, C. A. (2016). The Pros and cons of getting engaged in an online social community embedded within digital cognitive behavioral therapy for insomnia: Survey among users. Journal of Medical Internet Research, 18(4), 1-13. https://doi.org/10.2196/jmir.5654

11. Moore, D., Ayers, S., \& Drey, N. (2016). A Thematic Analysis of Stigma and Disclosure for Perinatal Depression on an Online Forum. JMIR Mental Health, 3(2), e18. https://doi.org/10.2196/mental.5611

12. Schippinger, M., Liebmann, P., Ruckenstuhl, P., Leithner, A., \& Bernhardt, G. (2016). Like or Dislike? Impact of Facebook on Ewing Sarcoma Treatment. JMIR Cancer, 2(2), e11. https://doi.org/10.2196/cancer.5367

13. Rademacher, M. A. (2018). "The most inspiring bikini photos you'll see this summer": A thematic analysis of mass audiences' interpretations of ostomy selfies. New Media and Society. https://doi.org/10.1177/1461444818761876

14. Tsuya, A., Sugawara, Y., Tanaka, A., \& Narimatsu, H. (2014). Do cancer patients tweet? Examining the twitter use of cancer patients in Japan. Journal of Medical Internet Research, 16(5), 1-11. https://doi.org/10.2196/jmir.3298

15. Merolli M, Gray K, Martin-Sanchez F. Therapeutic affordances of social media: emergent themes from a global online survey of people with chronic pain. J Med Internet Res. 2014 Dec;16(12).

16. Hanauer, S. (2006). Inflammatory Bowel Disease: Epidemiology, Pathogenesis, and Therapeutic Opportunities. Inflamm Bowel Dis. Volume 12, Supplement 1,

17. Head, K. A., Jurenka, J. S., \& Ascp, M. T. (2003). Inflammatory Bowel Disease Part I: Pathophysiology and Conventional and Alternative Treatment Options - 247.pdf, 8(3). Retrieved from http://www.altmedrev.com/publications/8/3/247.pdf

18. Crohn's and Colitis UK. (2017). What are the symptoms? Retrieved from: https://www.crohnsandcolitis.org.uk/about-inflammatory-bowel-disease/what-are-thesymptoms

19. Chan, J. M., Carroll, M. W., Smyth, M., Hamilton, Z., Prosser, R., Evans, D., ... Jacobson, K. (2018). A215 CHANGING INCIDENCE OF INFLAMMATORY BOWEL DISEASE IN THE PEDIATRIC POPULATION OF BRITISH COLUMBIA . Journal of the Canadian Association of Gastroenterology, 1(suppl_1), 376-377. https://doi.org/10.1093/jcag/gwy008.216

20. Kemp, K., Griffiths, J., \& Lovell, K. (2012). Understanding the health and social care needs of people living with IBD: A meta-synthesis of the evidence. World Journal of Gastroenterology, 18(43), 6240-6249. https://doi.org/10.3748/wjg.v18.i43.6240

21. Crohn's and Colitis UK. (2017). Surgery for Crohn's Disease. Retrieved from http://s3-euwest-1.amazonaws.com/files.crohnsandcolitis.org.uk/Publications/surgery-for-crohnsdisease.pdf

22. Lönnfors, S., Vermeire, S., Greco, M., Hommes, D., Bell, C., \& Avedano, L. (2014). IBD and health-related quality of life - Discovering the true impact. European Crohn's and Colitis Organisation, (October), 1281-1286.

23. Liu, L., Inkpen, K., Pratt, W. (2015). "I'm Not Like My Friends": Understanding How Children with a Chronic Illness Use Technology to Maintain Normalcy. CSCW 2015 Proceedings. Vancouver, Canada.

24. Carter, B., Qualter, P., Dix, D. (2015). Social relationships, loneliness and adolescence: The potential for disruption by chronic illness. Journal of Child Health Care 2015, Vol. 19(4) 421-422 
25. Hall, NJ., Rubin, GP., Dougall, A., Hungin, AP., \& Neely J. (2005). The fight for 'healthrelated normality': a qualitative study of the experiences of individuals living with established inflammatory bowel disease (ibd) J Health Psychol. 2005;10:443-455

26. Burger, JL. (2005). Living with inflammatory bowel disease: bodily and social responses to illness. St. 7-B. Louis, MO: Saint Louis University,

27. Zhang, X., Liu, S., Chen, X., Wang, L., Gao, B., \& Zhu, Q. (2017). Health information privacy concerns, antecedents, and information disclosure intention in online health communities. Information and Management, 55(4), 482-493. https://doi.org/10.1016/j.im.2017.11.003

28. Maloney-Krichmar, D., \& Preece, J. (2002). The Meaning of an Online Health Community in the Lives of Its Members: Roles, Relationships and Group Dynamics.

29. Wang, X., Zhao, K., \& Street, N. (2017). Analyzing and predicting user participations in online health communities: A social support perspective. Journal of Medical Internet Research, 19(4). https://doi.org/10.2196/jmir.6834

30. Tanis, M. (2008). Health-Related On-Line Forums : What's the Big Attraction? HealthRelated On-Line Forums : What's the Big Attraction ?, 730(August). https://doi.org/10.1080/10810730802415316

31. Miller, K., Gergen, K. (1998). LIFE ON THE LINE: THE THERAPEUTIC POTENTIALS OF COMPUTER- MEDIATED CONVERSATION. Journal of Marital and Family Therapy. Vol. 24, No.2, 189-202.

32. Pennebaker, J. W. (1997). Writing About Emotional Experiences as a Therapeutic Process. Psychological Science, 8(3), 162-166. https://doi.org/10.1111/j.14679280.1997.tb00403.x

33. Wright, K.(2002) Social support within an on-line cancer community: an assessment of emotional support, perceptions of advantages and disadvantages, and motives for using the community from a communication perspective, Journal of Applied Communication Research, 30:3, 195-209, DOI: 10.1080/00909880216586

34. Facebook. (2016). What Names are Allowed on Facebook? Available online: https://web.archive.org/web/20160122072253/https://engb.facebook.com/help/112146705538576

35. Shoebotham, A., Coulson, N. S., \& Shoebotham MSc, A. (2016). Therapeutic Affordances of Online Support Group Use in Women With Endometriosis. Journal of Medical Internet Research, 18(5), e109-e119. https://doi.org/10.2196/jmir.5548

36. Coulson, N. S., Bullock, E., \& Rodham, K. (2017). Exploring the Therapeutic Affordances of Self-Harm Online Support Communities: An Online Survey of Members. JMIR Mental Health, 4(4), e44. https://doi.org/10.2196/mental.8084

37. Birch, J. (2014, July 3). Why everyone is talking about this wom- an's brave bikini photo. Women's Health. Retrieved from http://www.womenshealthmag.com/health/bethanytownsend- colostomy-bag-selfie

38. Guo, L., Reich, J., Groshek, J., \& Farraye, F. A. (2016). Social media use in patients with inflammatory bowel disease. Inflammatory Bowel Diseases, 22(5), 1231-1238. https://doi.org/10.1097/MIB.0000000000000713

39. Moorhead, S. A., Hazlett, D. E., Harrison, L., Carroll, J. K., Irwin, A., \& Hoving, C. (2013). A new dimension of health care: Systematic review of the uses, benefits, and limitations of social media for health communication. Journal of Medical Internet Research, 15(4), 1-25. https://doi.org/10.2196/jmir.1933 
40. Choudhury, M., Morris, M., \& White, R. (2014). Seeking and Sharing Health Information Online: Comparing Search Engines and Social Media. CHI 2014, April 26 - May 01 2014, Toronto, ON, Canada

41. Thackeray, R., Crookston, B., \& West, J. (2013). Correlates of Health-Related Social Media Use Among Adults. J Med Internet Res. 2013 Jan; 15(1): e21

42. Scanfeld D, Scanfeld V, Larson EL. Dissemination of health information through social networks: twitter and antibiotics. Am J Infect Control. 2010 Apr;38(3):182-8. doi: 10.1016/j.ajic.2009.11.004. http://europepmc.org/abstract/MED/20347636. [PMCID: PMC3601456] [PubMed: 20347636]

43. Hill, J. A., Agewall, S., Baranchuk, A., Booz, G. W., Borer, J. S., Camici, P. G., ... Vrints, C. (2019). Medical Misinformation: Vet the Message! Circulation: Genomic and Precision Medicine, 12(2), 80-82. https://doi.org/10.1161/CIRCGEN.118.002439

44. Statistica. (2019). Most popular social networks worldwide as of January 2019, ranked by number of active users (in millions). Available online:

https://www.statista.com/statistics/272014/global-social-networks-ranked-by-number-ofusers/

45. Zhang, Y., He, D., \& Sang, Y. (2013). Facebook as a platform for health information and communication: A case study of a diabetes group. Journal of Medical Systems, 37(3). https://doi.org/10.1007/s10916-013-9942-7

46. Huesch, M., Chetlen, A., Segel, J., \& Schetter, S. (2017). Frequencies of private mentions and sharing of mammography and breast cancer terms on facebook: A pilot study. Journal of Medical Internet Research, 19(6). https://doi.org/10.2196/jmir.7508

47. Antheunis, M., Tates, K., \& Nieboer, T. (2013). Patients' and health care professionals' use of social media in health care: Motives, barriers and expectations. Patient Education and Counseling 92 (2013) 426-431

48. Lapowsky, I. (2013). Ev Williams on Twitter's Early Years. Inc. Available online: https://www.inc.com/issie-lapowsky/ev-williams-twitter-earlyyears.html?cid=em01011week40day04b

49. Roccetti, M., Casari, A., \& Marfia, G. (2015). Inside Chronic Autoimmune Disease Communities, (August), 1089-1096. https://doi.org/10.1145/2808797.2808813

50. Signorini, A., Segre, A. M., \& Polgreen, P. M. (2011). The Use of Twitter to Track Levels of Disease Activity and Public Concern in the U.S. during the Influenza A H1N1 Pandemic. PLoS ONE, 6(5), e19467. https://doi.org/10.1371/journal.pone.0019467

51. Heaivilin, N., Gerbert, B., Page, J.E. and Gibbs, J.L., 2011. Public health surveillance of dental pain via Twitter. Journal of dental research, 90(9), pp.1047-1051.

52. Statistica

53. Szeto, W., Van Der Bent, A., Petty, C. R., Reich, J., Farraye, F., \& Fishman, L. N. (2018). Use of Social Media for Health-Related Tasks by Adolescents with Inflammatory Bowel Disease: A Step in the Pathway of Transition. Inflammatory Bowel Diseases, 24(6), 11141122. https://doi.org/10.1093/ibd/izy021

54. Andalibi, N., Ozturk, P., \& Forte, A. (2017). Sensitive Self-disclosures, Responses, and Social Support on Instagram: The Case of \#Depression. CSCW '17, February 25-March 01, 2017, Portland, OR, USA

55. Muralidhara, S., \& Paul, M. J. (2018). \#Healthy Selfies: Exploration of Health Topics on Instagram. JMIR Public Health and Surveillance, 4(2), e10150. https://doi.org/10.2196/10150 
56. Holland, G., \& Tiggemann, M. (2017). "Strong beats skinny every time": Disordered eating and compulsive exercise in women who post fitspiration on Instagram. International Journal of Eating Disorders, 50(1), 76-79. https://doi.org/10.1002/eat.22559

57. Lup, K., Trub, L., \& Rosenthal, L. (2015). Instagram \#Instasad?: Exploring Associations Among Instagram Use, Depressive Symptoms, Negative Social Comparison, and Strangers Followed. Cyberpsychology, Behavior, and Social Networking, 18(5), 247-252. https://doi.org/10.1089/cyber.2014.0560

58. Moreno, M. A., Ton, A., Selkie, E., \& Evans, Y. (2017). Secret Society 123: Understanding the Language of Self-Harm on Instagram, 58(1), 78-84. https://doi.org/10.1016/j.jadohealth.2015.09.015.Secret

59. Gibson, J. J. (1977). The Theory of Affordance. In Perceiving Acting and Knowing.

60. Tembeck, T. (2016). Selfies of Ill Health: Online Autopathographic Photography and the Dramaturgy of the Everyday. Social Media + Society. January-March 2016: 1-11

61. Cover, R. (2013). Becoming and belonging: Performativity, subjectiv- ity, and the cultural purposes of social networking. In A. Poletti \& J. Rak (Eds.), Identity technologies: Constructing the self online (pp. 55-69). Madison: The University of Wisconsin Press.

62. Hanna, P. (2012). Using internet technologies (such as Skype) as a research medium: a research note. Qualitative Research 12(2) 239-242

63. Seitz, S. (2016). Pixilated partnerships, overcoming obstacles in qualitative interviews via Skype: a research note. Qualitative Research, 16(2), 229-235. https://doi.org/10.1177/1468794115577011

64. Choi, M., Kim, S., Lee, S., Kwon, BC., Yi5, JS., Choo, J., Huh, J. (2017). Toward Predicting Social Support Needs in Online Health Social Networks.

65. Coulson, N. (2015). Patterns of engagement with inflammatory bowel disease online support groups: Comparing posters and lurkers. Gastroenterology Nursing, 38(5), 348-353. https://doi.org/10.1097/SGA.0000000000000131

66. Jenkins, H., Ford, S. and Green, J. (2013). Spreadable media. 1st ed. New York: New York University Press.

67. Lave, J., \& Wenger, E. (1991). Situated learning. Legitimate peripheral participation. Cambridge: University of Cambridge Press.

68. Wang, Y., Kraut, R., Levine, J. To Stay or Leave? The Relationship of Emotional and Informational Support to Commitment in Online Health Support Groups. CSCW 2012, February 11-15, 2012, Seattle, Washington., USA.

69. DiCicco-Bloom, B. and Crabtree, B.F., 2006. The qualitative research interview. Medical education, 40(4), pp.314-321.

70. Stewart Loane, S., \& D'Alessandro, S. (2014). Empowered and knowledgeable health consumers: The impact of online support groups on the doctor-patient relationship. Australasian Marketing Journal, 22(3), 238-245. https://doi.org/10.1016/j.ausmj.2014.08.007

71. Malik, S., \& Coulson, N. S. (2011). The Therapeutic Potential of the Internet: Exploring Selfhelp Processes in an Internet Forum for Young People With Inflammatory Bowel Disease. Gastroenterology Nursing, 34(6), 439-448. https://doi.org/10.1097/SGA.0b013e318237a9ba

72. Roccetti, M., Salomoni, P., Prandi, C., Marfia, G., Montagnani, M., \& Gningaye, L. (2016). Understanding Crohn's disease patients reaction to infliximab from facebook: A medical perspective. Proceedings of the 2016 IEEE/ACM International Conference on Advances in Social Networks Analysis and Mining, ASONAM 2016, (Cd), 1007-1010. https://doi.org/10.1109/ASONAM.2016.7752364 
73. Frohlich, D. O. (2016). The Social Construction of Inflammatory Bowel Disease Using Social Media Technologies. Health Communication, 31(11), 1412-1420.

https://doi.org/10.1080/10410236.2015.1077690

74. Stastistica. (2019). Number of monthly active Facebook users worldwide as of 1st quarter 2019 (in millions). Available online: https://www.statista.com/statistics/264810/number-ofmonthly-active-facebook-users-worldwide/

75. Get Your Belly Out. (n.d.). Get Your Belly Out Facebook Page. Available online: https://www.facebook.com/pg/getyourbellyout/about/?ref=page_internal

76. Pershad, Y., Hangge, P. T., Albadawi, H., \& Oklu, R. (2018). Social Medicine: Twitter in Healthcare. Journal of Clinical Medicine, 7(6). https://doi.org/10.3390/jcm7060121

77. Rains, S., Peterson, E., \& Wright, K. (2015). Communicating Social Support in Computermediated Contexts: A Meta-analytic Review ofContent Analyses Examining Support Messages Shared Online among Individuals Coping withIllness, Communication Monographs, 82:4, 403-430, DOI: 10.1080/03637751.2015.1019530

78. Riaz, M. S., \& Atreja, A. (2016). Personalized Technologies in Chronic Gastrointestinal Disorders: Self-monitoring and Remote Sensor Technologies. Clinical Gastroenterology and Hepatology: The Official Clinical Practice Journal of the American Gastroenterological Association, 14(12), 1697-1705. https://doi.org/10.1016/j.cgh.2016.05.009

79. Con, D., \& De Cruz, P. (2016). Mobile Phone Apps for Inflammatory Bowel Disease SelfManagement: A Systematic Assessment of Content and Tools. JMIR MHealth UHealth, 4(1), e13. https://doi.org/10.2196/mhealth.4874

80. Braithwaite, D., Waldron, V., Finn, J. (1999). Communication of Social Support in Computer-Mediated Groups for People with Disabilities. Health Communication, 11 (2), 123-151.

81. Coulson, N. S. (2017). Affordance theory can help understanding of individuals' use of online support communities. British Journal of Health Psychology, 22(3), 379-382. https://doi.org/10.1111/bjhp.12247

82. Kosyfaki, C., Angelova, N., Tsohou, A., \& Magkos, E. (2017). The Privacy Paradox in the Context of Online Health Data Disclosure by Users. European, Mediterranean, and Middle Eastern Conference on Information Systems

83. Crohn's and Colitis UK. (n.d.). Crohn's \& Colitis UK Forum on Facebook. Available online: https://www.facebook.com/groups/CCUKforum/

84. Obar, J. A., \& Wildman, S. (2015). Social media definition and the governance challenge: An introduction to the special issue. Telecommunications Policy. https://doi.org/10.1016/j.telpol.2015.07.014

85. Wright, K. B., Bell, S. B., Wright, K. B., \& Bell, S. B. (2003). Health-related Support Groups on the Internet: Linking Empirical Findings to Social Support and Computer-mediated Communication Theory. Journal of Health Psychology, 8(1), 39-54. https://doi.org/10.1177/1359105303008001429

86. Mander, J. (2015). Internet Users Have Average of 5.54 Social Media Accounts. Available online: https://blog.globalwebindex.com/chart-of-the-day/internet-users-have-average-of-554-social-media-accounts/

87. Norman, D. (1988). The psychology of everyday things. New York, NY: Basic Books. Office for National Statistics

88. Hutchby, I. (2001). “Technology, Texts, and Affordances.” Sociology. May 2001 vol. 35 no. 2. 441-456. 
89. Zhao, Y., Liu, J., Tang, J., \& Zhu, Q. (2013). Conceptualizing perceived affordances in social media interaction design. Aslib Proceedings, 65, 289-303.

https://doi.org/10.1108/00012531311330656

90. Bernardi, R. (2016). How do online communities of patients aggregate on twitter? An affordance perspective. In 2016 International Conference on Information Systems, ICIS 2016.

91. Patterson, H. (2013). Contextual Expectations of Privacy in Self-Generated Health Information Flows. In TPRC 41: The 41st Research Conference on Communication, Information and Internet Policy (pp. 1-48). https://doi.org/http://dx.doi.org/10.2139/ssrn.2242144

92. Brady, E., Segar, J., \& Sanders, C. (2016). "I always vet things": Navigating privacy and the presentation of self on health discussion boards among individuals with long-term conditions. Journal of Medical Internet Research, 18(10). https://doi.org/10.2196/jmir.6019

93. Marwick, a. E., \& Boyd, D. (2010). I tweet honestly, I tweet passionately: Twitter users, context collapse, and the imagined audience. New Media \& Society, 13(1), 114-133. https://doi.org/10.1177/1461444810365313 